\title{
Diet Practices, Body Mass Index, and Oral Health-Related Quality of Life in Adults with Periodontitis- A Case-Control Study
}

\author{
Galit Almoznino ${ }^{1,2,3, *}$, Naama Gal ${ }^{4}$, Liran Levin ${ }^{5}{ }^{(0)}$, Eitan Mijiritsky ${ }^{6}{ }^{\circledR}$, Guy Weinberg ${ }^{7}$, \\ Ron Lev ${ }^{7}$, Avraham Zini ${ }^{8}$, Riva Touger-Decker ${ }^{9}$, Daniella Chebath-Taub ${ }^{3}$ and Boaz Shay ${ }^{3}$ \\ 1 Big Biomedical Data Research Laboratory, Hebrew University-Hadassah School of Dental Medicine, \\ Jerusalem 91120, Israel \\ 2 Department of Oral Medicine, Sedation \& Maxillofacial Imaging, Hebrew University-Hadassah School of \\ Dental Medicine, Jerusalem 91120, Israel \\ 3 Department of Endodontics, Hebrew University-Hadassah School of Dental Medicine, Jerusalem 91120, \\ Israel; dentidoc10@gmail.com (D.C.-T.); boaz@endo.co.il (B.S.) \\ 4 In partial fulfillment of DMD degree, Hebrew University-Hadassah School of Dental Medicine, Jerusalem \\ 91120, Israel; alonnaama@gmail.com \\ 5 Department of Periodontology, Faculty of Medicine and Dentistry, University of Alberta, Edmonton, \\ AB T6G, Canada; liran@ualberta.ca \\ 6 Department of Otolaryngology, Head and Neck and Maxillofacial Surgery, Tel-Aviv Sourasky Medical \\ Center, Sackler Faculty of Medicine, Tel Aviv 6139001, Israel; mijiritsky@bezeqint.net \\ 7 Department of Periodontology, Oral and Maxillofacial Center, Tel-Hashomer 5262000, Israel; \\ guy.weinberg@gmail.com (G.W.); drronlev@gmail.com (R.L.) \\ 8 Department of Community Dentistry, Hebrew University-Hadassah School of Dental Medicine, \\ Jerusalem 91120, Israel; aviz@hadassah.org.il \\ 9 Rutgers School of Dental Medicine, Newark, NJ 07107, USA; decker@shp.rutgers.edu \\ * Correspondence: galit@almoznino.com; Tel.: +972-2-677-6194
}

Received: 22 February 2020; Accepted: 25 March 2020; Published: 30 March 2020

\begin{abstract}
Objectives: To assess and compare diet practices, body mass index (BMI), and oral health-related quality of life (OHRQoL) in adults with and without periodontitis. Methods: Demographics, health-related behaviors, BMI, dental and periodontal parameters, diet practices, and Oral Health Impact Profile-14 (OHIP-14) were collected from 62 periodontitis patients and 100 controls without periodontitis. Results: Having periodontitis was positively associated with male sex $(p=0.004)$, older age $(p<0.001)$, smoking pack-years $(p=0.006)$, weight $(p=0.008)$, BMI $(p=0.003)$, number of meals per day $(p<0.001)$ and had a negative association with decayed teeth $(p=0.013)$, alcohol $(p=0.006)$, and sweets $(p=0.007)$ consumption. Periodontitis patients were more likely to avoid carbonated beverages $(p=0.028)$, hot $(p=0.003)$, and cold drinks $(p=0.013)$, cold $(p=0.028)$, hard textured $(p=0.002)$, and fibrous foods $(p=0.02)$ than the controls, and exhibited higher global OHIP-14 $(p<0.001)$ and most domain scores. Age $(p<0.001)$, BMI $(p=0.045)$, number of meals per day $(p=0.024)$, and global OHIP-14 score $(p<0.001)$ remained positively associated with periodontitis in the multivariate analysis. Conclusions: Periodontitis patients exhibited higher BMI and altered diet practices and OHRQoL as compared to controls. Assessment of diet practices, BMI, and OHRQoL should be part of periodontal work-up. Dentists and dietitians should collaborate to design strategies to address these challenges.
\end{abstract}

Keywords: periodontitis; diet; body mass index (BMI); quality of life; oral health-related quality of life (OHRQoL) 


\section{Introduction}

There is a synergism between diet, nutrition, and the integrity of the oral cavity in health and illness [1]. Compromised oral health may impact functional abilities in regards to the ingestion of foods and fluids [2]. Over time, this can result in nutritional deficiencies and malnutrition which may, in turn, reduce resistance to infection and compromise tissue healing [3,4].

Periodontitis is a biofilm-induced chronic inflammatory disease that consists of loss of periodontal attachment, which eventually leads to tooth loss [5]. Assessing diet practices in patients with periodontitis is important for several reasons. First, tooth loss due to periodontitis may lead to an altered ability to bite and chew food. Prior research has revealed inverse associations between tooth loss and nutrient intake as well as diet quality [6-8]. Vice versa, poor nutrition such as reduced intake of carotin, vitamin A, C, dairy food, as well as vegetables were found to be correlated with loss of teeth [9].

Second, pain due to periodontitis may reduce appetite and subsequently alter the diet. Previous studies have shown that pain and discomfort in oral mucosa may negatively impact food intake and limit the types of food eaten $[2,10]$.

A third reason to consider is the systemic impacts of nutrition and periodontal disease and their associations. Evidence of the effect of nutritional imbalance on cellular and molecular levels suggests that nutrition has the potential to affect biological gradient and thus affect periodontal infections [11]. Accordingly, periodontal diseases develop faster in undernourished populations [11]. Food intake is not a treatment for oral and dental diseases, but deficiencies of these nutrients can negatively impact tissue integrity, inflammation, bone mineralization, immune responses, and wound healing [12,13]. It is beyond the scope of this paper to review these mechanisms.

Oral health-related quality of life (OHRQoL) is a conceptual model that evaluates the functional, psychological, and social aspects and pain concerning oral and facial conditions [14]. An association exists between diet quality and better OHRQoL [15] and vice versa. We have previously demonstrated that OHRQoL was significantly impaired in patients with disorders of nutrition [16]. In the context of periodontitis, previous studies have shown that in patients with periodontitis, the OHRQoL is impaired compared with subjects without periodontitis [17-19].

To our knowledge, papers assessing the associations between having a diagnosis of periodontitis and diet practices, body mass index (BMI), and OHRQoL, while controlling for demographics, health-related habits, and dental and periodontal status, have not been published in the English language literature. This study hypothesized that there would be a correlation between the existence of periodontitis and higher BMI, altered diet practices and OHRQoL. To assess the hypothesis of the study, the research aimed to measure and compare BMI, diet practices, and OHRQoL between subjects with and without periodontitis who attended routine dental screenings and analyze the association between the existence of periodontitis and the following parameters: demographics, health-related behaviors, BMI, dental and periodontal parameters, diet practices, and OHRQoL.

\section{Subjects and Methods}

\subsection{Study Population}

The research was performed between January 1st, 2014 and June 30th, 2014, at the Department of Periodontology, Oral and Maxillofacial Center, Tel- Hashomer, Israel. The Oral and Maxillofacial facility is located at Sheba Hospital, which is the largest medical center in Israel and among the larger Middle East medical centers. The Department of Periodontology is a secondary dental facility that coordinates referrals nationwide from dozens of dental clinics of patients who need periodontal counseling and management.

The periodontitis group was composed of 62 consecutive subjects that were diagnosed with periodontitis at the Department of Periodontology. The control group was composed of one hundred consecutive subjects who attended the Conservative Dentistry Department of this Oral and Maxillofacial 
Center, for elective dental screenings without a history of periodontitis (i.e., the same target population without the disease under investigation). All subjects were examined at their first visit before dental and/or periodontal treatment. At the completion of the examination, the subjects were provided with a written report detailing their dental and oral status and any diagnosed mucosal lesions, and this examination was recorded in their dental file. Patients were advised to seek consultation and treatment according to their findings.

WINPEPI softwarewas used to conduct sample size calculation [20] and showed that at least 147 subjects, composed of two groups that have a 40:60 ratio (92 subjects in one group and 55 subjects in the second group) were required to achieve eighty percent statistical power to distinguish a 4.48-point difference in Oral Health Impact Profile-14 (OHIP-14 global score, considering that $\alpha=5 \%$, and that the approximated standard deviations are 9.93 (of the group with highest standard deviation) and 8.25 (of the group with the lowest standard deviation),considering our previous publication assessing OHIP-14 [21].

Ethical issues: The research complies with the STrengthening the Reporting of OBservational studies in Epidemiology (STROBE) protocol. The study was approved by the Tel Hashomer institutional review board (approval number 1133-2011-version 3). All subjects signed informed consent before their participation in the research.

Eligibility criteria: To diminish confounding factors like aging and morbidity on periodontitis, diet practices as well as OHRQoL, the research solely included young to middle-aged participants without co-morbid physical disability and/or systemic disease (e.g., diabetes, cardiovascular diseases, malignant diseases, etc.) The reason for exclusion is that these diseases can increase the risk of inflammation and periodontitis as well as affect nutritional practices and the OHRQoL.

Inclusion criteria: new subjects attending elective dental examinations, age range: 18-55.

Exclusion criteria: urgent medical and/or dental/periodontal condition; disorders of nutrition; psychiatric conditions and/or using medications that affect mental state (e.g., antidepressants and benzodiazepines); drug, medications and/or alcohol abuse; physical disabilities; systemic diseases (e.g., diabetes, cardiovascular diseases, malignant diseases, etc.); immune-compromised status induced by chemotherapy, radiotherapy and/or chronic steroids use, pregnancy or lactation. The periodontitis group was diagnosed using the American Academy of Periodontology 1999 criteria [22,23]. Periodontal therapy six months before attendance was considered an exclusion criterion for the periodontitis group [24,25].

\subsection{Collected Data}

Questionnaires: The research included a self-administered questionnaire filled by the patients during the first appointment. Variables in the questionnaire were defined as follows:

Socio-demographic variables: (a) Age was presented in years; (b) Sex: male/ female;(c) Education was presented in years of schooling; (d) Country of the birth variable included: Africa, Asia, 'West' (North and South America, Europe, Australia), Former Soviet Union Israel and others, as described previously [16].

\subsection{Health-Related Habits Variables}

Smoking cigarettes, hookah and alcohol consumptions, and physical activity were described as yes/no questions. In addition, we performed a calculation of smoking pack-years by multiplying the number of packs smoked per day by the number of years of smoking [21]. Definitions of alcohol consumption habits and physical activity were described previously $[21,26,27]$.

\subsection{Oral Health-Related Quality of Life (OHRQoL).}

The validated Hebrew version of the OHIP-14 [28] was used as a tool to measure OHRQoL [14]. OHIP-14 and domain scores were analyzed as continuous variables. The methods related to the 
application and analysis of the OHIP-14 score are described in detail in our prior published studies $[16,21,29-32]$.

\subsection{The DietPractices Questionnaire}

Assessment of diet practices was done using a two-page modified food frequency questionnaire (FFQ) with additional questions assessing self-reported diet practices, which was developed by a U.S. Registered Dietitian (R.T.D.) and was subjected to content validation and reviewed by experts in nutrition practice and research [2] and has been used previously [2,16,33]. This questionnaire evaluated the frequency of consumption of the following food groups: fruits (fresh uncooked), salad or other raw, fresh vegetables, cooked vegetables, dairy products, carbohydrate-rich foods (e.g., bread, cereal, rolls, bagels), fish or meat, eggs, oil products, snacks (cracker, popcorn, bagel, nuts), sweets (croissant, chocolate, cookies, etc.), strawberries or other citrus fruit, tomatoes, fried foods [2,16]. The frequency of food group consumption was categorized on an ordinal scale as never, 1-2 servings/week, 3-4servings/week, 5-6servings/week, or daily [2,16,33]. The subjects were also asked to indicate if they avoid (yes/no) any of the following: sauces, seasonings, chewing gum, herbs, sparkling water, non-carbonated and carbonated beverages, and drinks they considered hot or cold, along with foods they considered hot, cold, hard, or fibrous texture. Subjects also indicated the number of meals per day, and whether they had followed a weight control diet in the past year $[2,16,33]$.

\subsection{Clinical Examination}

All subjects underwent a clinical examination that included height, weight, and calculation of BMI as well as dental and periodontal examinations. The examiners (GW and DST) completed a training and calibration session to ensure mutual concurrence and appropriate interpretation of the indices measures employed in the research. All clinical examinations were performed on the subjects with periodontitis as well as on the controls.

Body Mass Index (BMI): Height, weight was measured and BMI was defined as the weight (in kilograms) in light clothing divided by height squared (in meters) [34]. BMI was analyzed as a continuous parameter.

Dental and periodontal examinations: were performed by the aid of light, a dental mirror, and a standard periodontal probe. Radiological evaluation incorporated vertical bilateral bitewings including the molar and premolar areas as well as parallel periapical radiographs of the incisors in the maxilla and mandible. Radiographs were performed in the same appointment as the clinical examination and the questionnaire. The following measurements were included:

1. DMFT index (Decay, Missing, and Filled Teeth) was used for caries status assessment, following the WHO criteria. The calculation included 28 teeth (third molars were excluded) (http://www2.paho.org/hq/dmdocuments/2009/OH_st_Esurv.pdf). Whilst the missing teeth (M) ingredient of the DMFT index contains teeth missing only due to caries, in adults, particularly in periodontitis, determination of the specific reason for tooth loss can be a challenge [17]. Therefore, the present study included missing teeth of any reason and was not limited to dental caries.

2. Plaque Index (PI): a measurement of oral hygiene by calculating the percentage of teeth with visible plaque presence on any tooth surface (third molars teeth excluded) [35].

3. Probing depth (PD) and bleeding on probing (BOP). The six Ramfjord index teeth (teeth number: $16,21,24,36,41,44)$ and the remaining molar teeth 26,46 , were clinically tested. Ramfjord index teeth are well known as a representative of the different types of teeth [36]. Six points around the tooth were used for each index measurement $[17,37,38]$. For probing depth, the value of the highest measurement was recorded and the value for the bleeding score was calculated as the percent of bleeding pockets from the total pockets measured [37]. 


\subsection{Statistical Analysis}

Analysis of the data was performed with the SPSS software version 22.0 (Chicago, Illinois, United States) and statistical significance was defined as a p-value of less than 5 percent. Continuous variables were presented as means and standard deviations. The categorical variables were presented as percentages and frequencies.

Tests to assess associations and correlations between the groups' parameter (periodontitis vs. controls) as a dependent variable and the independent variables included: Person Chi-square, Fisher's exact test or likelihood ratio for categorical variables, as well as an analysis of variance (ANOVA) test for the numerical variables. Based on the univariant results, the significant independent parameters were selected for logistic regression analysis (with the groups' parameter as a dependent variable).

\section{Results}

A total of 162 subjects (100 in the control group and 62 in the periodontitis group) participated in the study with a mean age of $26.77 \pm 9.11$ years. Table 1 presents the demographics and health-related habits of the study population. Compared to controls, those in the periodontitis group were significantly more likely to be male $(p=0.004)$, older $(p<0.001)$, and to have more smoking pack-years $(p=0.006)$. There was a negative association between the periodontitis group and alcohol consumption $(p=0.006)$. The periodontitis and the controls did not statistically significantly differ regarding birth country $(p=0.343)$, smoking cigarettes $(p=0.746)$ and hookah $(p=0.224)$, physical activity $(p=0.668)$, the performance of a weight control diet during the past year $(p=0.145)$, and years of schooling $(p=0.300)$ (Table 1).

Table 1. Demographics and health-related habits of the study population.

\begin{tabular}{|c|c|c|c|c|c|c|c|c|}
\hline \multirow{2}{*}{ Parameter } & \multirow{2}{*}{ Variable } & \multicolumn{2}{|c|}{ Periodontitis } & \multicolumn{2}{|c|}{ Control } & \multicolumn{2}{|c|}{ Total } & \multirow{2}{*}{$p$ Value } \\
\hline & & $\mathbf{N}$ & $\%$ & $\mathbf{N}$ & $\%$ & $\mathbf{N}$ & $\%$ & \\
\hline \multirow{2}{*}{ Sex } & Male & 52 & 83.9 & 63 & 63 & 115 & 71 & \multirow{2}{*}{$0.004 *$} \\
\hline & Female & 10 & 16.1 & 37 & 37 & 47 & 29 & \\
\hline \multirow{7}{*}{ Birth country } & Africa & 1 & 1.6 & 0 & 0 & 1 & 0.6 & \multirow{7}{*}{$0.343^{* *}$} \\
\hline & Asia & 0 & 0 & 1 & 1 & 1 & 0.6 & \\
\hline & West & 2 & 3.2 & 3 & 3 & 5 & 3 & \\
\hline & FSU & 7 & 11.3 & 12 & 12 & 19 & 11.7 & \\
\hline & Israel & 49 & 79 & 82 & 82 & 131 & 80.9 & \\
\hline & Other & 3 & 4.8 & 2 & 2 & 5 & 3 & \\
\hline & No & 53 & 85.5 & 76 & 76 & 129 & 79.6 & \\
\hline \multirow{2}{*}{ Smoking Cigarettes } & Yes & 22 & 35.5 & 33 & 33 & 55 & 34 & \multirow{2}{*}{0.746 * } \\
\hline & No & 40 & 64.5 & 67 & 67 & 107 & 66 & \\
\hline \multirow{2}{*}{ Smoking Hookah } & Yes & 11 & 17.7 & 26 & 26 & 37 & 22.8 & \multirow{2}{*}{0.224 * } \\
\hline & No & 51 & 82.3 & 74 & 74 & 125 & 77.2 & \\
\hline \multirow{2}{*}{ Alcohol consumption } & Yes & 38 & 61.3 & 81 & 81 & 119 & 73.5 & \multirow{2}{*}{$0.006 *$} \\
\hline & No & 24 & 38.7 & 19 & 19 & 43 & 26.5 & \\
\hline \multirow{2}{*}{ Physical Activity } & Yes & 50 & 80.6 & 78 & 78 & 128 & 79 & \multirow{2}{*}{0.688 * } \\
\hline & No & 12 & 19.4 & 22 & 22 & 34 & 21 & \\
\hline \multirow{2}{*}{$\begin{array}{l}\text { Performed a weight } \\
\text { control diet during the } \\
\text { past year }\end{array}$} & Yes & 9 & 14.5 & 24 & 24 & 33 & 20.4 & \multirow{2}{*}{0.145 * } \\
\hline & No & 53 & 85.5 & 76 & 76 & 129 & 79.6 & \\
\hline
\end{tabular}


Table 1. Cont.

\begin{tabular}{|c|c|c|c|c|c|c|}
\hline & & & & 95\% Confidence Int & val of Mean & \\
\hline Para & neter & $\mathbf{N}$ & Mean \pm SD & Moan Jowor Round & Mean Upper & $p$ Value \\
\hline & Control & 100 & $23.27 \pm 5.85$ & 22.11 & 24.43 & \\
\hline Age & Periodontitis & 62 & $32.42 \pm 10.54$ & 29.74 & 35.10 & $<0.001 \wedge$ \\
\hline & Total & 162 & $26.77 \pm 9.11$ & 25.36 & 28.19 & \\
\hline & Control & 100 & $13.15 \pm 1.93$ & 12.77 & 13.53 & \\
\hline rears or & Periodontitis & 60 & $13.52 \pm 2.49$ & 12.87 & 14.16 & $0.300^{\wedge}$ \\
\hline & Total & 160 & $13.29 \pm 2.15$ & 12.95 & 13.62 & \\
\hline & Control & 100 & $0.9 \pm 2.8$ & 0.4 & 1.5 & \\
\hline Smoking & Periodontitis & 62 & $3.0 \pm 6.4$ & 1.4 & 4.6 & $0.006^{\wedge}$ \\
\hline Pack Years & Total & 161 & $1.7 \pm 4.6$ & 1.0 & 2.5 & \\
\hline
\end{tabular}

*Pearson Chi-square; ** likelihood ratio; ^ ANOVA.

Table 2 presents BMI, dental and periodontal parameters of the study population. Those in the periodontitis group were significantly more likely to be of a higher weight $(p=0.008)$ and BMI $(p=0.003)$, have more missing-M and $(p<0.001)$ filled teeth-F $(p=0.007)$, and higher DMFT scores $(p=0.006)$, probing depth $(p<0.001)$, and plaque index scores $(p<0.001)$. Being in the periodontitis group was negatively associated with having decayed teeth- $\mathrm{D}(p=0.013)$. There were no significant differences between the periodontitis and the control groups regarding height $(p=0.103)$ and bleeding score $(p=0.912)$ (Table 2$)$.

Table 2. Anthropometrics, dental and periodontal parameters of the study population.

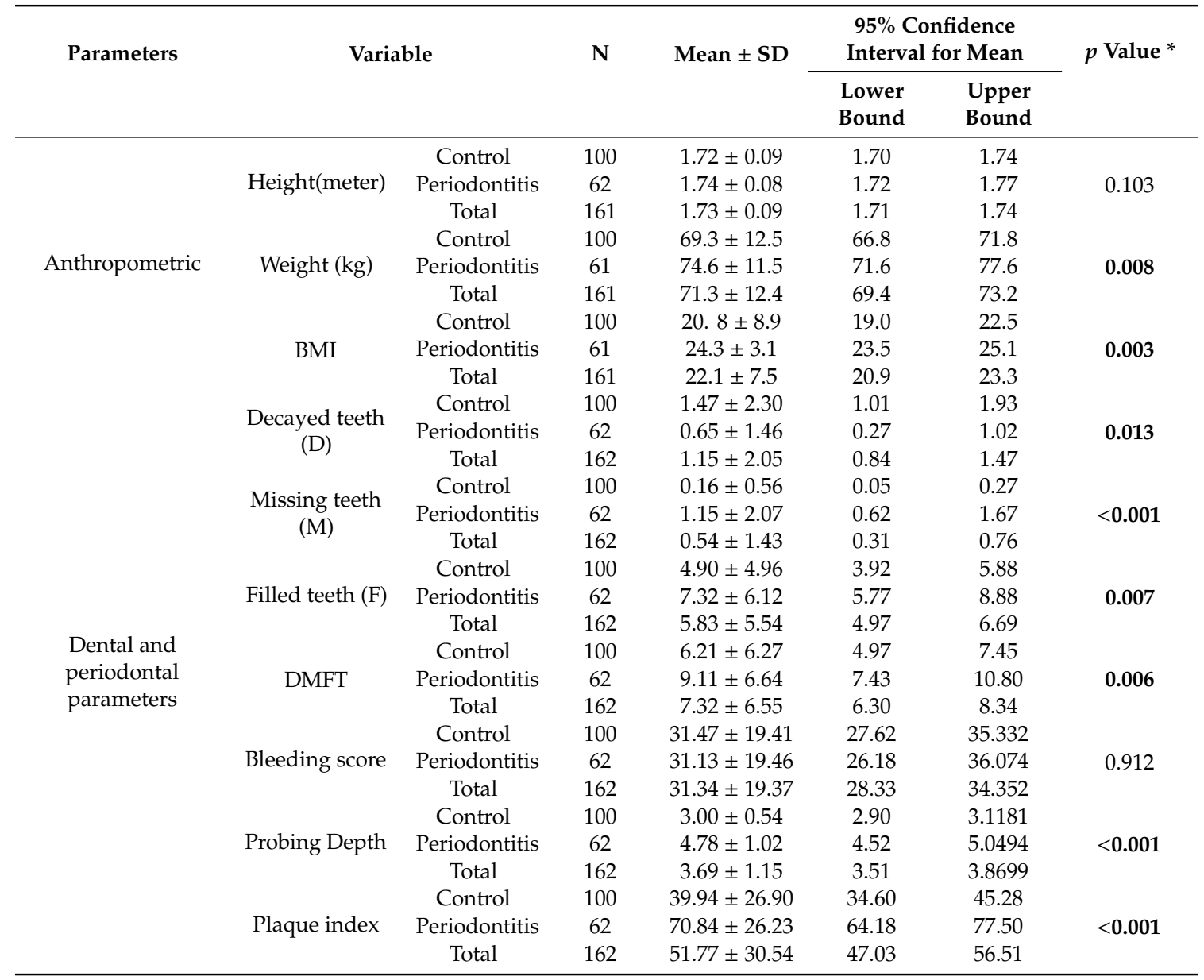

${ }^{*}$ ANOVA. The bold is statistically significant result. 
Table 3 presents the statistically significant differences in the diet practices between the two groups. Being in the periodontit is group was positively associated with the number of meals per day $(p<0.001)$ and negatively associated with the frequency of eating sweets $(p=0.007)$. Compared to controls, those in the periodontitis group were significantly more likely to avoid consumption of carbonated beverages $(p=0.028)$, and drinks they considered hot $(p=0.003)$ and cold $(p=0.013)$, and foods they considered cold $(p=0.028)$, hard textured $(p=0.002)$, and fibrous $(p=0.02)$ (Table 3). Overall, for all the questions of foods, one might avoid, a greater proportion of individuals with periodontitis were more likely to avoid specific types of fluids and foods than those without periodontitis.

Table 3. Frequency of consumption and avoidance patterns of specific food groups among the study population * Pearson Chi-square, ^ likelihood ratio ** Fisher's exact test.

\begin{tabular}{|c|c|c|c|c|c|c|c|c|}
\hline \multirow{2}{*}{ Variable } & \multirow{2}{*}{$\begin{array}{l}\text { Frequency of } \\
\text { Consumption }\end{array}$} & \multicolumn{2}{|c|}{ Control } & \multicolumn{2}{|c|}{ Periodontitis } & \multicolumn{2}{|c|}{ Total } & \multirow{2}{*}{$p$ Value } \\
\hline & & $\mathbf{N}$ & $\%$ & $\mathbf{N}$ & $\%$ & $\mathbf{N}$ & $\%$ & \\
\hline \multirow{4}{*}{ Meals/Day } & 1 & 2 & 2 & 2 & 3.2 & 4 & 2.5 & \multirow{4}{*}{$<0.001^{\wedge}$} \\
\hline & 2 & 29 & 29 & 24 & 39.3 & 53 & 32.9 & \\
\hline & 3 & 69 & 69 & 25 & 41 & 94 & 58.4 & \\
\hline & $4<$ & 0 & 0 & 10 & 16.4 & 10 & 6.2 & \\
\hline \multirow{5}{*}{ 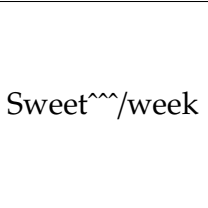 } & 0 & 9 & 9 & 5 & 8.1 & 14 & 8.6 & \multirow{5}{*}{0.007 * } \\
\hline & $1-2$ & 32 & 32 & 35 & 56.5 & 67 & 41.4 & \\
\hline & $3-4$ & 32 & 32 & 13 & 21 & 45 & 27.8 & \\
\hline & $5-6$ & 16 & 16 & 9 & 14.5 & 25 & 15.4 & \\
\hline & Daily & 11 & 11 & 0 & 0 & 11 & 6.8 & \\
\hline \multirow{2}{*}{ Variable } & \multirow{2}{*}{$\begin{array}{l}\text { Do you avoid } \\
\text { the foods? }\end{array}$} & \multicolumn{2}{|c|}{ Control } & \multicolumn{2}{|c|}{ Periodontitis } & \multicolumn{2}{|c|}{ Total } & \multirow{2}{*}{$p$-Value ${ }^{*}$} \\
\hline & & $\mathbf{N}$ & $\%$ & $\mathbf{N}$ & $\%$ & $\mathbf{N}$ & $\%$ & \\
\hline \multirow{2}{*}{$\begin{array}{c}\text { Carbonated } \\
\text { beverage }\end{array}$} & Yes & 2 & 2 & 7 & 11.3 & 9 & 5.6 & \multirow{2}{*}{$0.028^{* *}$} \\
\hline & No & 98 & 98 & 55 & 88.7 & 153 & 94.4 & \\
\hline \multirow{2}{*}{ Hot drinks } & Yes & 2 & 2 & 7 & 11.3 & 9 & 5.6 & \multirow{2}{*}{$0.028^{* *}$} \\
\hline & No & 98 & 98 & 55 & 88.7 & 153 & 94.4 & \\
\hline \multirow{2}{*}{ Cold drinks } & Yes & 0 & 0 & 6 & 9.7 & 6 & 3.7 & \multirow[b]{2}{*}{$0.003 * *$} \\
\hline & No & 100 & 100 & 56 & 90.3 & 156 & 96.3 & \\
\hline \multirow{2}{*}{ Cold food } & Yes & 1 & 1 & 6 & 9.7 & 7 & 4.3 & \multirow{2}{*}{$0.013^{* *}$} \\
\hline & No & 99 & 99 & 56 & 90.3 & 155 & 95.7 & \\
\hline \multirow{2}{*}{$\begin{array}{l}\text { Hard texture } \\
\text { food }\end{array}$} & Yes & 2 & 2 & 6 & 9.7 & 8 & 4.9 & \multirow{2}{*}{0.028 * } \\
\hline & No & 98 & 98 & 56 & 90.3 & 154 & 95.1 & \\
\hline Fibrous food & Yes & 1 & 1 & 8 & 12.9 & 9 & 5.6 & $0.002 * *$ \\
\hline
\end{tabular}

There were no significant differences between the groups in the frequency of consumption of fruits $(p=0.762)$, salad or fresh vegetables $(p=0.651)$, cooked vegetables $(p=0.862)$, dairy $(p=0.142)$, carbohydrate rich foods $(p=0.252)$, fish or meat $(p=0.681)$, eggs $(p=0.667)$, oil products $(p=0.553)$, snacks $(p=0.220)$, strawberries $(p=0.143)$, citrus fruits $(p=0.133)$, tomatoes $(p=0.281)$, fried food $(p=0.861)$. Additionally, there were no statistically significant differences between the periodontitis and the control groups regarding avoidance of sauces $(p=1.00)$, seasonings $(p=1.00)$, herbs $(p=1.00)$, and chewing gum $(p=0.069)$.

Analysis of OHIP-14 domains and global scores of the study population are presented in Table 4. Compared to the control group, those in the periodontitis group exhibited significantly higher global OHIP $(p<0.001)$ and domain scores [except the social disability scores $(p=0.052$, which is close to statistical significance)]. The highest score was noted in the physical pain domain, while the lowest mean score was noted in the functional limitation domain. 
Table 4. The Mean Oral Health Impact Profile Scores (OHIP-14) global and domain scores of the study population.

\begin{tabular}{|c|c|c|c|c|c|c|}
\hline & & \multirow{2}{*}{$\mathbf{N}$} & \multirow{2}{*}{ Mean \pm SD } & \multicolumn{2}{|c|}{$\begin{array}{l}\text { 95\% Confidence } \\
\text { Interval for Mean }\end{array}$} & \multirow{2}{*}{$\begin{array}{c}{ }^{*} p \text { between } \\
\text { Groups }\end{array}$} \\
\hline & & & & $\begin{array}{l}\text { Lower } \\
\text { Bound }\end{array}$ & $\begin{array}{l}\text { Upper } \\
\text { Bound }\end{array}$ & \\
\hline OHIP & Control & 100 & $0.1 \pm 0.3$ & 0.05 & 0.2 & \\
\hline \multirow{2}{*}{$\begin{array}{c}\text { 1+2Functional } \\
\text { limitation }\end{array}$} & Periodontitis & 62 & $0.3 \pm 0.6$ & 0.1 & 0.4 & 0.018 \\
\hline & Total & 162 & $0.2 \pm 0.4$ & 0.1 & 0.2 & \\
\hline \multirow{3}{*}{$\begin{array}{c}\text { OHIP } 3+4 \\
\text { Physical pain }\end{array}$} & Control & 100 & $0.6 \pm 0.6$ & 0.5 & 0.7 & \\
\hline & Periodontitis & 62 & $1.1 \pm 1.0$ & 0.9 & 1.4 & $<0.001$ \\
\hline & Total & 162 & $0.8 \pm 0.9$ & 0.7 & 0.9 & \\
\hline OHIP & Control & 100 & $0.4 \pm 0.7$ & 0.3 & 0.5 & \\
\hline \multirow{2}{*}{$\begin{array}{l}\text { 5+6Psychological } \\
\text { discomfort }\end{array}$} & Periodontitis & 62 & $0.70 \pm 0.92$ & 0.5 & 0.9 & 0.021 \\
\hline & Total & 162 & $0.51 \pm 0.79$ & 0.4 & 0.6 & \\
\hline \multirow{3}{*}{$\begin{array}{c}\text { OHIP } 7+8 \\
\text { Physical disability }\end{array}$} & Control & 100 & $0.2 \pm 0.4$ & 0.1 & 0.3 & \\
\hline & Periodontitis & 62 & $0.5 \pm 0.8$ & 0.3 & 0.7 & 0.013 \\
\hline & Total & 162 & $0.3 \pm 0.6$ & 0.2 & 0.4 & \\
\hline OHIP 9+10 & Control & 100 & $0.3 \pm 0.5$ & 0.2 & 0.4 & \\
\hline \multirow{2}{*}{$\begin{array}{l}\text { Psychological } \\
\text { disability }\end{array}$} & Periodontitis & 62 & $0.8 \pm 0.9$ & 0.5 & 1.0 & $<0.001$ \\
\hline & Total & 162 & $0.5 \pm 0.7$ & 0.3 & 0.6 & \\
\hline \multirow{3}{*}{$\begin{array}{c}\text { OHIP } 11+12 \\
\text { Social disability }\end{array}$} & Control & 100 & $0.2 \pm 0.4$ & 0.1 & 0.3 & \\
\hline & Periodontitis & 62 & $0.4 \pm 0.7$ & 0.2 & 0.6 & 0.052 \\
\hline & Total & 162 & $0.3 \pm 0.5$ & 0.2 & 0.4 & \\
\hline \multirow{3}{*}{$\begin{array}{c}\text { OHIP 13+14 } \\
\text { Handicap }\end{array}$} & Control & 100 & $0.1 \pm 0.3$ & 0.1 & 0.2 & \\
\hline & Periodontitis & 62 & $0.4 \pm 0.7$ & 0.3 & 0.6 & $<0.001$ \\
\hline & Total & 162 & $0.3 \pm 0.5$ & 0.2 & 0.3 & \\
\hline \multirow{3}{*}{$\begin{array}{l}\text { OHIP-14 global } \\
\text { score }\end{array}$} & Control & 100 & $4.0 \pm 4.6$ & 3.1 & 4.9 & \\
\hline & Periodontitis & 62 & $8.6 \pm 9.5$ & 6.2 & 11.0 & $<0.001$ \\
\hline & Total & 161 & $5.8 \pm 7.2$ & 4.6 & 6.9 & \\
\hline
\end{tabular}

${ }^{*}$ ANOVA. The bold is statistically significant result.

Multivariable logistic regression analysis was performed with the parameters that had significant associations/correlations with the periodontitis group compared to the control group in the univariate statistical analyses. Multivariate analysis revealed that compared to the control group, those in the periodontitis group were significantly more likely to eat more meals per day $(p=0.024$,standard error [SE]: 0.41, odds ratio $2.54,95 \%$ confidence interval [CI]:1.13-5.69), be older $(p<0.001, \mathrm{SE}=0.035$, $\mathrm{OR}=1.15,95 \%$ CI: 1.07-1.23), have a higher global OHIP-14 score $(p<0.001, \mathrm{SE}=0.43, \mathrm{OR}=1.16$, 95\% CI:1.06-1.26), and have a higher BMI $(p=0.045, \mathrm{SE}=0.04, \mathrm{OR}=1.09,95 \% \mathrm{CI} 1.01-1.20)$. The Nagelkerke R square, which represents the proportion of the total variability that the model explains was $71 \%$.

\section{Discussion}

To our knowledge, associations between diet practices and OHRQoL in adults with periodontitis in comparison to a control sample have not been published in the English literature. We explored these associations in addition to important potential confounding parameters such as demographics, health-related habits, BMI, and dental and periodontal status. The results of the current research confirmed our hypothesis that adult patients with periodontitis have altered diet practices and lower OHRQoL compared to individuals without periodontitis.

Associations between periodontitis and demographic characteristics, health-related habits, BMI, dental and periodontal parameters, and OHRQoL.

Demographics characteristics and periodontitis. Subjects with and without periodontitis did not statistically significantly differ regarding birth country and years of schooling. However, male sex 
and older age had a positive association with having a diagnosis of periodontitis as compared to not having it.

Sex. Robust evidence from systematic reviews and cross-sectional studies show that the prevalence of periodontitis is lower in females compared to males [39-41]. However, men do not seem to be at increased risk for more periodontal loss compared to women [39]. Instead, sex differences are attributed to poorer oral hygiene, less favorable attitudes toward oral health, and poor dental-visit behavior among males than to any genetic factors [42].

Age. Of all the demographic characteristics that were analyzed, only age retained a statistically significant positive correlation with periodontitis in the multivariate analysis. Consistent with our findings, the likelihood of developing the periodontal disease rises with age in populations all over the globe, which suggests that age is a significant risk indicator [43]. The new staging and grading framework of periodontitis classification states that age can increase the risk for future progression of alveolar bone loss [44]. Nevertheless, since both groups were not comparable in terms of age group, and since age retained a significant statistical association in the multivariate analysis, we may attribute some of the impacts on oral health and food intake to the age factor rather just periodontitis.

Education. Interestingly, in the present study, we found no statistical difference of positive and negative periodontitis related to years of education, in contrast to other studies that show that increased risk of periodontitis is associated with low level of education [45].

Our findings suggest that high risk behaviors such as alcohol consumption, smoking, and food consumption are influenced from hypersensitivities and pain related to periodontitis, rather than of higher education. Indeed, it had been previously revealed that there is an insufficient level of awareness of cardiovascular risk factors, even among medical students [46].

Health-related habits and periodontitis. The periodontitis group had a positive association with smoking pack-years and a negative association with alcohol consumption.

Smoking. Although smoking (yes/no) did not differ between the groups, smoking pack-years, indicative of both the amount and time of consumption, were positively associated with periodontitis. Consistent with this finding, there is accumulating evidence for a higher prevalence of periodontitis among smokers [43]. Smoking is considered the second most important risk factor (after inadequate plaque control) in the etiology and pathogenesis of periodontitis [47] and a grade modifier in the new classification [44].

Alcohol. Alcohol consumption among controls was higher compared to the periodontitis group. A possible explanation for the avoidance of alcohol could be dentinal hypersensitivity, consistent with reports of a higher rate of dentinal hypersensitivity in patients with periodontitis [48]. In an in-vitro study, it has been shown under an electron microscope scanning that red and white wine has an etching effect, which results in greater exposure of dentinal tubules and thus increases sensitivity [49]. Furthermore, alcohol has been found in literature as a condition that may worsen periodontitis [50].

BMI and periodontitis. Those in the periodontitis group had a higher BMI compared to controls. While both fell within the "normal weight" range as defined for BMI (18.5-24.9), the mean BMI was clinically and statistically significantly higher (24.3) in the periodontitis group compared to the controls (20.8). The definition of overweight is a BMI of 25.0-30.0 [51].Associations between obesity and periodontitis have been published [52,53], although the causal evidence is lacking [54]. The chronic inflammatory state and oxidative stress which lead to the development of insulin resistance may be involved in the association between obesity and periodontal disease [55].

Dental and periodontal parameters and periodontitis. Those in the periodontitis group had less tooth decay than those in the control group. Findings concerning the relationship between periodontitis and dental caries are contradictory. Prior research on this association has been heterogeneous, some has documented a positive association [56], however, recent research showed a negative correlation between the severity of periodontitis and caries prevalence [57], which is consistent with our findings. A possible explanation for the lower decay score among the periodontitis group (see Table 2), could be 
our finding of a lower consumption rate of sweets in the periodontitis group (see Table 3) that had been demonstrated in the study.

As expected, missing teeth, probing depth, and plaque index were found to be higher in the periodontitis group than in the control group. The higher number of missing teeth among patients with periodontitis (see Table 2) could account for the avoidance of certain foods. The majority of research regarding tooth loss and diet has been done with older adults and demonstrates that those adults with tooth loss consume significantly lower amounts of fresh fruits and vegetables than those with complete dentition [6]. Using the National Health and Nutrition Examination Survey (NHANES) data, Zhu and Hollis found that adults age 19 years of age and older with 20 or fewer teeth consumed lower quality diets and lower intakes of fruits, vegetables, and whole grains than adults with 21-27 teeth [6].

It is also important to assess plaque index as a possible confounder since the plaque index is directly affected by diet habits and can vary depending on types of foods consumed and oral hygiene practices [58]. The bleeding score could result from extensive carious lesions involving the gingiva and not necessarily from periodontitis, which can explain why this parameter was not significantly different between the groups.

Diet practices and periodontitis. Although those in the periodontitis group were more likely to eat 4 or more meals per day than those in the control group, this only represented $16.4 \%$ of the population and $42.5 \%$ only ate 1-2 meals per day. Those in the periodontitis group more often avoided alcohol, sweets, carbonated beverages, hot and cold drinks, cold food, hard textured and fibrous foods more often than controls (Table 3). These observations could result from the fact that periodontitis is associated with gingival recessions and a high rate of dentinal hypersensitivity as well as with a higher number of missing teeth and as a result, reduced chewing ability. For example, the periodontitis group consumed fewer sweets, with $11 \%$ of the control group who eat sweets daily compared to $0 \%$ in the periodontitis group (Table 3). High osmotic stimuli such as sugar can result in fluid flow within the dentinal tubules and cause painful sensations [48]. It is also known that cemental exposure can cause sensitization to cold drinks and food [59,60]. Some studies suggest that carbonated beverages are a risk factor for developing periodontitis [61] attributed to chronic inflammation, due to their high dietary glycemic load [61]. It had been suggested that the periodontal health of patients could benefit from lowering carbonated beverage consumption [62].

The avoidance of foods in the periodontitis group considered hard or fibrous may be related to the greater degree of tooth loss in this group as compared to the control group. Prior research has shown that individuals with tooth loss are more likely to avoid foods they consider hard or fibrous [8,63]. In particular, reduced chewing capacity and the discomfort that characterizes periodontitis can affect the patient's diet [64]. The lack of significant differences in other food group intake, particularly for fruits and vegetables may be related to actual foods consumed. For example, in Israel, salads are often served chopped and the altered consistency may allow for positive adaptive behaviors in this regard. Further study in regards to specific foods with a larger sample is needed to explore these associations.

Oral health-related quality of life $(O H R Q o L)$ and periodontitis. Consistent with prior research $[17,19]$, in the present study, those in the periodontitis group exhibited significantly worse global OHIP scores as well as in most domain scores than those in the control group. Periodontitis had been shown to have a wide range of clinical characteristics that may adversely affect the OHRQoL [65]. The impact of periodontitis can be expressed in many ways including social, physical, and psychological means [66]. Additionally, OHRQoL had been shown to deteriorate with the increase in the severity of periodontitis [67]. The loss of periodontal tissues and greater numbers of missing teeth in patients with periodontitis may account for the functional limitations and increase in the OHIP-14 scores. Specifically, questions 7 and 8 in the OHIP-14 questionnaire, representing the physical disability domain (see Table 4), that asks about inadequate diet and stopping a meal because of dental, mouth, or dentures problems, can reveal the connection between food avoidance and low OHRQoL. Pain and discomfort associated with periodontitis could impact the physical pain domain of the OHIP-14 score, and indeed the physical pain domain achieved the highest OHIP-14 domain scores, suggesting that pain has the 
highest contribution in lowering OHRQoL in these patients. Findings suggested that periodontitis patients avoid hard and fibrous food, which may be attributed more to the impact of physical pain (which showed the highest mean score among other OHIP domains), rather to the impact of the functional limitations (which showed the lowest mean score among other OHIP domains). Finally, the OHRQoL retained its statistically significant association with periodontitis in the multivariate analysis, which considered many potential confounders.

Strengths and limitations. Strengths of this study include the relatively large sample size (162 subjects) and the strict protocol that employed standardized internationally accepted questionnaires of the OHIP-14 and the structured modified food frequency questionnaire (FFQ), as well as clinical examinations for all subjects that included BMI as well as DMFT index (Decay, Missing, and Filled Teeth) Plaque Index (PI), Probing depth (PD) and bleeding on probing (BOP). This will enable a future studied comparison with other populations with different socioeconomic and ethnic status. We diminished confounding factors such as aging and morbidity on periodontitis, diet practices, and OHRQoL, by including only young to middle-aged subjects without co-existing physical disabilities and/or systemic diseases.

The limitations of the study include the convenience samples which may limit the generalizability of the results. Nevertheless, the samples were composed of patients who were referred from multiple clinics serving different populations. Moreover, since we used a case-control study design, we could not presume causal relations between the variables, and therefore there is only a description of associations and correlations between the variables. While we analyzed numerous parameters, considering the depth and complexities of the issues, other parameters may impact the results that were not considered. There is a need for further longitudinal studies, that will be based on the new classification of periodontal conditions [68] in other settings and populations and in more ranges of age that will include laboratory analysis of chemical elements and bone metabolism to address these issues.

\section{Conclusions}

In this sample of patients, those with periodontitis exhibited impaired diet practices, higher BMI values, and worse OHRQoL compared to controls. These findings highlight the need for oral health practitioners to consider the assessment of diet practices, BMI, and OHRQoL as an integral part of a periodontitis evaluation and treatment plan. Dentists should refer patients with altered diet habits to a dietitian for care. Dentists and dietitians should collaborate to design strategies to address these challenges.

Author Contributions: Conceptualization, G.A. and B.S.; methodology, G.A., B.S.; software, A.Z.; validation, G.W., D.C.-T. and A.Z.; formal analysis, A.Z.; investigation, G.A., G.W., D.C.-T. and A.Z., X.X.; data curation, G.A.; writing—original draft preparation, N.G. and G.A., X.X.; writing—review and editing, L.L., E.M., G.Y., R.L., R.T.-D.; visualization, G.A.; supervision, G.A. and B.S.; project administration, G.A. All authors have read and agreed to the published version of the manuscript.

Funding: This research received no external funding.

Conflicts of Interest: The authors declare no conflict of interest.

\section{List of Abbreviations}

$\begin{array}{ll}\text { BOP } & \text { Bleeding upon probing } \\ \text { BMI } & \text { body mass index } \\ \text { DMFT } & \text { Decay, Missing, and Filled Teeth } \\ \text { OHIP-14 } & \text { Oral Health Impact Profile-14 } \\ \text { OHRQoL } & \text { Oral health-related quality of life } \\ \text { PI } & \text { Plaque index } \\ \text { PD } & \text { Probing depth }\end{array}$




\section{References}

1. Touger-Decker, R.; Mobley, C. Position of the academy of nutrition and dietetics: Oral health and nutrition. J. Acad. Nutr. Diet. 2013, 113, 693-701. [CrossRef] [PubMed]

2. Czerninski, R.; Zadik, Y.; Kartin-Gabbay, T.; Zini, A.; Touger-Decker, R. Dietary alterations in patients with oral vesiculoulcerative diseases. Oral Surg. Oral Med. Oral Pathol. Oral Radiol. 2014, 117, 319-323. [CrossRef] [PubMed]

3. Sheetal, A.; Hiremath, V.K.; Patil, A.G.; Sajjansetty, S.; Kumar, S.R. Malnutrition and its oral outcome-A review. J. Clin. Diagn. Res. 2013, 7, 178-180. [CrossRef] [PubMed]

4. Scardina, G.A.; Messina, P. Good oral health and diet. J. Biomed. Biotechnol. 2012, 2012, 720692. [CrossRef] [PubMed]

5. Needleman, I.; Garcia, R.; Gkranias, N.; Kirkwood, K.L.; Kocher, T.; Iorio, A.D.; Moreno, F.; Petrie, A. Mean annual attachment, bone level, and tooth loss: A systematic review. J. Clin. Periodontol. 2018, 45 (Suppl. 20), S112-S129. [CrossRef]

6. Zhu, Y.; Hollis, J.H. Tooth loss and its association with dietary intake and diet quality in American adults. J. Dent. 2014, 42, 1428-1435. [CrossRef]

7. Tada, A.; Miura, H. Association between mastication and cognitive status: A systematic review. Arch. Gerontol. Geriatr. 2017, 70, 44-53. [CrossRef]

8. Cousson, P.Y.; Bessadet, M.; Nicolas, E.; Veyrune, J.L.; Lesourd, B.; Lassauzay, C. Nutritional status, dietary intake and oral quality of life in elderly complete denture wearers. Gerodontology 2012, 29, e685-e692. [CrossRef]

9. Wakai, K.; Naito, M.; Naito, T.; Kojima, M.; Nakagaki, H.; Umemura, O.; Yokota, M.; Hanada, N.; Kawamura, T. Tooth loss and intakes of nutrients and foods: A nationwide survey of Japanese dentists. Community Dent. Oral Epidemiol. 2010, 38, 43-49. [CrossRef]

10. Ni Riordain, R.; Meaney, S.; McCreary, C. Impact of chronic oral mucosal disease on daily life: Preliminary observations from a qualitative study. Oral Dis. 2011, 17, 265-269. [CrossRef]

11. Enwonwu, C.O. Interface of malnutrition and periodontal diseases. Am. J. Clin. Nutr. 1995, 61, 430S-436S. [CrossRef]

12. Hujoel, P.P.; Lingstrom, P. Nutrition, dental caries and periodontal disease: A narrative review. J. Clin. Periodontol. 2017, 44 (Suppl. 18), S79-S84. [CrossRef]

13. Dommisch, H.; Kuzmanova, D.; Jonsson, D.; Grant, M.; Chapple, I. Effect of micronutrient malnutrition on periodontal disease and periodontal therapy. Periodontol. 2000 2018, 78, 129-153. [CrossRef]

14. Slade, G.D. Derivation and validation of a short-form oral health impact profile. Community Dent. Oral Epidemiol. 1997, 25, 284-290. [CrossRef]

15. Huang, C.J.; Hu, H.T.; Fan, Y.C.; Liao, Y.M.; Tsai, P.S. Associations of breakfast skipping with obesity and health-related quality of life: Evidence from a national survey in Taiwan. Int. J. Obes. (Lond.) 2010, 34, 720-725. [CrossRef]

16. Shay, B.; Ben Ami, O.; Levy Ianculovici, D.; Zini, A.; Ianculovici, C.; Almoznino, G. Oral health-related quality of life in patients with disorders of nutrition. J. Oral Rehabil. 2019, 46, 355-368. [CrossRef]

17. Levin, L.; Zini, A.; Levine, J.; Weiss, M.; Lev, R.; Chebath Taub, D.; Hai, A.; Almoznino, G. Demographic profile, Oral health impact profile and dental anxiety scale in patients with chronic periodontitis: A case-control study. Int. Dent. J. 2018, 68, 269-278. [CrossRef]

18. Levin, L.; Zini, A.; Levine, J.; Weiss, M.; Lev, R.A.; Hai, A.; Chebath-Taub, D.; Almoznino, G. Dental anxiety and oral health-related quality of life in aggressive periodontitis patients. Clin. Oral Investig. 2018, 22, 1411-1422. [CrossRef]

19. Al Habashneh, R.; Khader, Y.S.; Salameh, S. Use of the arabic version of oral health impact profile-14 to evaluate the impact of periodontal disease on oral health-related quality of life among Jordanian adults. J. Oral Sci. 2012, 54, 113-120. [CrossRef]

20. Abramson, J.H. WINPEPI (PEPI-for-Windows): Computer programs for epidemiologists. Epidemiol. Perspect. Innov. 2004, 1, 6. [CrossRef]

21. Almoznino, G.; Aframian, D.J.; Sharav, Y.; Sheftel, Y.; Mirzabaev, A.; Zini, A. Lifestyle and dental attendance as predictors of oral health-related quality of life. Oral Dis. 2015, 21, 659-666. [CrossRef] [PubMed] 
22. Periodontology, A.A. international international workshop for a classification of periodontal diseases and conditions. papers. oak brook, illinois, October 30-November 2, 1999. Ann. Periodontol. 1999, 4, 1-112.

23. Periodontology, A.A. American Academy of Periodontology: Task force report on the update to the 1999 classification of periodontal diseases and conditions. J. Periodontol. 2015, 86, 835-838.

24. Saito, A.; Kikuchi, M.; Ueshima, F.; Matsumoto, S.; Hayakawa, H.; Masuda, H.; Makiishi, T. Assessment of oral self-care in patients with periodontitis: A pilot study in a dental school clinic in Japan. BMC Oral Health 2009, 9, 27. [CrossRef]

25. Meusel, D.R.; Ramacciato, J.C.; Motta, R.H.; Brito Junior, R.B.; Florio, F.M. Impact of the severity of chronic periodontal disease on quality of life. J. Oral Sci. 2015, 57, 87-94. [CrossRef]

26. Nandi, A.; Glymour, M.M.; Subramanian, S.V. Association among socioeconomic status, health behaviors, and all-cause mortality in the United States. Epidemiology 2014, 25, 170-177. [CrossRef]

27. Dawson, D.A. Methodological issues in measuring alcohol use. Alcohol. Res. Health 2003, 27, 18-29.

28. Kushnir, D.; Zusman, S.P.; Robinson, P.G. Validation of a Hebrew version of the Oral Health Impact Profile 14. J. Public Health Dent. 2004, 64, 71-75. [CrossRef]

29. Almoznino, G.; Zini, A.; Aframian, D.J.; Kaufman, E.; Lvovsky, A.; Hadad, A.; Levin, L. Oral health related quality of life in young individuals with dental anxiety and exaggerated gag reflex. Oral Health Prev. Dent. 2015, 13, 435-440.

30. Almoznino, G.; Zini, A.; Zakuto, A.; Sharav, Y.; Haviv, Y.; Hadad, A.; Chweidan, H.; Yarom, N.; Benoliel, R. Oral health-related quality of life in patients with temporomandibular disorders. J. Oral Facial Pain Headache 2015, 29, 231-241. [CrossRef]

31. Almoznino, G.; Benoliel, R.; Lobbezoo, F.G.L. Use and misuse of guidelines in dental sleep medicine. In Textbook "Sleep Medicine and Dentistry", 2nd ed.; Gilles Lavigne, P.P.C., Ed.; Quintessence Publishing: Tokio, Japan, 2019.

32. Almoznino, G.; Benoliel, R.; Sharav, Y.; Haviv, Y. Sleep disorders and chronic craniofacial pain: Characteristics and management possibilities. Sleep Med. Rev. 2017, 33, 39-50. [CrossRef]

33. Eklund, S.; Moller, I.J.; LeClercq, M. Calibration of Examiners for Oral Epidemiological Surveys; ORH/EIS/EPID.93.1; World Health Organization: Geneva, Switzerland, 1993.

34. Leiba, A.; Twig, G.; Vivante, A.; Skorecki, K.; Golan, E.; Derazne, E.; Tzur, D.; Grossman, E.; Dichtiar, R.; Kark, J.D.; et al. Prehypertension among 2.19 million adolescents and future risk for end-stage renal disease. J. Hypertens. 2017, 35, 1290-1296. [CrossRef] [PubMed]

35. Loe, H.; Silness, J. Periodontal disease in pregnancy. I. prevalence and severity. Acta Odontol. Scand. 1963, 21, 533-551. [CrossRef] [PubMed]

36. Kingman, A.; Susin, C.; Albandar, J.M. Effect of partial recording protocols on severity estimates of periodontal disease. J. Clin. Periodontol. 2008, 35, 659-667. [CrossRef]

37. Beltran-Aguilar, E.D.; Eke, P.I.; Thornton-Evans, G.; Petersen, P.E. Recording and surveillance systems for periodontal diseases. Periodontol. 2000 2012, 60, 40-53. [CrossRef]

38. Weinberg, M.A.; Hassan, H. Bleeding on probing: What does it mean? Gen. Dent. 2012, 60, 271-276.

39. Shiau, H.J.; Reynolds, M.A. Sex differences in destructive periodontal disease: A systematic review. J. Periodontol. 2010, 81, 1379-1389. [CrossRef]

40. Sculean, A. Editorial: Common risk factors for dental caries and periodontal diseases? Oral Health Prev. Dent. 2017, 15, 5 .

41. Figueiredo, A.; Soares, S.; Lopes, H.; dos Santos, J.N.; Ramalho, L.M.; Cangussu, M.C.; Cury, P.R. Destructive periodontal disease in adult Indians from Northeast Brazil: Cross-sectional study of prevalence and risk indicators. J. Clin. Periodontol. 2013, 40, 1001-1006. [CrossRef]

42. Burt, B. Position paper: Epidemiology of periodontal diseases. J. Periodontol. 2005, 76, 1406-1419.

43. AlJehani, Y.A. Risk factors of periodontal disease: Review of the literature. Int. J. Dent. 2014, $2014,182513$. [CrossRef] [PubMed]

44. Tonetti, M.S.; Greenwell, H.; Kornman, K.S. Staging and grading of periodontitis: Framework and proposal of a new classification and case definition. J. Periodontol. 2018, 89 (Suppl. 1), S159-S172. [CrossRef] [PubMed]

45. Ng, S.K.; Leung, W.K. Oral health-related quality of life and periodontal status. Community Dent. Oral Epidemiol. 2006, 34, 114-122. [CrossRef] 
46. Maksimović, M.Ž.; Marinković, J.M.; Vlajinac, H.D.; Maksimović, J.M.; Tomanić, M.S.; Radak, D.J. Wien Klin Wochenschr. Awareness and knowledge of cardiovascular disease risk factors among medical students. Wien. klinische Wochenschrift 2017, 129, 458-463.

47. Rosa, E.F.; Corraini, P.; de Carvalho, V.F.; Inoue, G.; Gomes, E.F.; Lotufo, J.P.; De Micheli, G.; Pannuti, C.M. A prospective 12-month study of the effect of smoking cessation on periodontal clinical parameters. J. Clin. Periodontol. 2011, 38, 562-571. [CrossRef]

48. Bartold, P.M. Dentinal hypersensitivity: A review. Aust. Dent. J. 2006, 51, 212-218. [CrossRef]

49. Addy, M.; Absi, E.G.; Adams, D. Dentine hypersensitivity. The effects in vitro of acids and dietary substances on root-planed and burred dentine. J. Clin. Periodontol. 1987, 14, 274-279. [CrossRef]

50. Park, J.B.; Han, K.; Park, Y.G.; Ko, Y. Association between alcohol consumption and periodontal disease: The 2008 to 2010 Korea National Health and Nutrition Examination Survey. J. Periodontol. 2014, 85, 1521-1528. [CrossRef]

51. CDC. Defining Adult Overweight and Obesity. Available online: https://www.cdc.gov/obesity/adult/defining. html (accessed on 28 November 2019).

52. Martens, L.; De Smet, S.; Yusof, M.Y.; Rajasekharan, S. Association between overweight/obesity and periodontal disease in children and adolescents: A systematic review and meta-analysis. Eur. Arch. Paediatr. Dent. 2017, 18, 69-82. [CrossRef]

53. Keller, A.; Rohde, J.F.; Raymond, K.; Heitmann, B.L. Association between periodontal disease and overweight and obesity: A systematic review. J. Periodontol. 2015, 86, 766-776. [CrossRef]

54. Shungin, D.; Cornelis, M.C.; Divaris, K.; Holtfreter, B.; Shaffer, J.R.; Yu, Y.H.; Barros, S.P.; Beck, J.D.; Biffar, R.; Boerwinkle, E.A.; et al. Using genetics to test the causal relationship of total adiposity and periodontitis: Mendelian randomization analyses in the Gene-Lifestyle Interactions and Dental Endpoints (GLIDE) Consortium. Int. J. Epidemiol. 2015, 44, 638-650. [CrossRef]

55. Martinez-Herrera, M.; Silvestre-Rangil, J.; Silvestre, F.J. Association between obesity and periodontal disease. A systematic review of epidemiological studies and controlled clinical trials. Med. Oral Patol. Oral Cir. Bucal 2017, 22, e708-e715. [CrossRef]

56. Merchant, A.T. Periodontitis and dental caries occur together. J. Evid. Based Dent. Pract. 2012, 12 (Suppl. 3), 18-19. [CrossRef]

57. Nascimento, G.G.; Baelum, V.; Dahlen, G.; Lopez, R. Methodological issues in assessing the association between periodontitis and caries among adolescents. Community Dent. Oral Epidemiol. 2018, 46, 303-309. [CrossRef]

58. Moynihan, P.; Petersen, P.E. Diet, nutrition and the prevention of dental diseases. Public Health Nutr. 2004, 7, 201-226. [CrossRef]

59. Rees, J.S.; Addy, M. A cross-sectional study of dentine hypersensitivity. J. Clin. Periodontol. 2002, 29, 997-1003. [CrossRef]

60. Naidu, G.M.; Ram, K.C.; Sirisha, N.R.; Sree, Y.S.; Kopuri, R.K.; Satti, N.R.; Thatimatla, C. Prevalence of dentin hypersensitivity and related factors among adult patients visiting a dental school in andhra pradesh, southern India. J. Clin. Diagn. Res. 2014, 8, ZC48-ZC51. [CrossRef]

61. Fann, J.C.; Lai, H.; Chiu, S.Y.; Yen, A.M.; Chen, S.L.; Chen, H.H. A population-based study on the association between the intake of soft drinks and periodontal disease in Taiwanese adults aged 35-44 years (KCIS no. 33). Public Health Nutr. 2016, 19, 1471-1478. [CrossRef]

62. Song, I.S.; Han, K.; Ko, Y.; Park, Y.G.; Ryu, J.J.; Park, J.B. Associations between the consumption of carbonated beverages and periodontal disease: The 2008-2010 Korea national health and nutrition examination survey. Medicine (Baltim.) 2016, 95, e4253. [CrossRef]

63. Zelig, R.; Jones, V.M.; Touger-Decker, R.; Hoskin, E.R.; Singer, S.R.; Byham-Gray, L.; Radler, D.R.; Rothpletz-Puglia, P. The eating experience: Adaptive and maladaptive strategies of older adults with tooth loss. JDR Clin. Trans. Res. 2019, 4, 217-228. [CrossRef]

64. Budtz-Jorgensen, E.; Chung, J.P.; Mojon, P. Successful aging-The case for prosthetic therapy. J. Public Health Dent. 2000, 60, 308-312. [CrossRef]

65. Cunha-Cruz, J.; Hujoel, P.P.; Kressin, N.R. Oral health-related quality of life of periodontal patients. J. Periodontal Res. 2007, 42, 169-176. [CrossRef]

66. Needleman, I.; McGrath, C.; Floyd, P.; Biddle, A. Impact of oral health on the life quality of periodontal patients. J. Clin. Periodontol. 2004, 31, 454-457. [CrossRef] 
67. Wellapuli, N.; Ekanayake, L. Association between chronic periodontitis and oral health-related quality of life in Sri Lankan adults. Int. Dent. J. 2016, 66, 337-343. [CrossRef]

68. Papapanou, P.N.; Sanz, M.; Buduneli, N.; Dietrich, T.; Feres, M.; Fine, D.H.; Flemmig, T.F.; Garcia, R.; Giannobile, W.V.; Graziani, F.; et al. Periodontitis: Consensus report of workgroup 2 of the 2017 World Workshop on the Classification of Periodontal and Peri-Implant Diseases and Conditions. J. Periodontol. 2018, 89 (Suppl. 1), S173-S182. [CrossRef]

(C) 2020 by the authors. Licensee MDPI, Basel, Switzerland. This article is an open access article distributed under the terms and conditions of the Creative Commons Attribution (CC BY) license (http://creativecommons.org/licenses/by/4.0/). 